\title{
Correlation of Body Perceptions and Eating Disorders of 9-12 years old Children in Bratislava
}

\section{Róbert Osad'an - Erika Drgoňová ${ }^{*}$}

\begin{abstract}
The purpose of this study is to evaluate children in Bratislava, Slovakia. The survey sample consisted of 276 children aged $9-12$ who were tested using the Children's Eating Attitude Test as a diagnostic tool for testing young people, who show a proclivity towards having eating issues, a possibility of anorexia, or a possible problem with bulimic tendencies. The study analyses the components of the test and the scores of children to whom it was administered, and come to conclusions as to its usefulness in diagnosing eating issues in children between grades 4 and 6 . It also examines the comparisons between the children in Slovakia and the children in Australian studies in order to see if the scores correlate and what similarities and differences are present between the two groups studied.
\end{abstract}

Key words: children, test, perception, eating disorders

\section{Introduction}

Body image discontentment has been linked to inferior psychological health and can pave the way for the onset of unhealthy, improper eating habits in puberty and later life. Described as disapproval of specific features of one's appearance, body image dissatisfaction occurs when a person's perception of his or her physical appearance does not agree with the qualities he or she would like to possess. Unless addressed, preteens' negative perceptions of their body are prone to cause eating issues during adolescence and in adulthood. Through this study, the factors that need to be addressed, with regard to body image perceptions in connection with eating disorders, can be determined. With the valuable data in hand, both the children's families and their school teachers will have a concrete basis from where to start educating their kids about the vital aspects of their health that correlates to their eating patterns. This can subsequently help the children to learn to differentiate between the realities of physical growth and the rhetoric of cultural representations of "ideal" bodies.

\footnotetext{
Róbert Osad'an, Comenius Universtity in Bratislava, Bratislava, Slovakia; osadan@fedu.uniba.sk

Erika Drgoňová, ZŠ Ostredková 14, Bratislava, Slovakia; drgonova.skola14ba@gmail.com
} 
Eating disorders, especially Anorexia Nervosa and Bulimia Nervosa, have gained an incremental public awareness in the past four decades or so. Needless to say, the steady increase in the number of recorded cases of eating disorders (particularly in young and adolescent females) triggered reactions from various social groups that advocate children and women welfare. As a matter of fact, research done by Steiner and Lock (1998) as well as Lucas et al. (1991) revealed that the incidence of these eating disorders has increased dramatically for the last 20 years without any evidence of abatement. Countless studies and research have also proven that examining the manifestation of certain eating disorders among children as well as adolescents, should be taken seriously since the age range of people with irregular eating behavior now extends to children in the early elementary school age, according to Bryant-Waugh and Lask (1995). The more alarming issue is that the prevalence of eating disorders among young and adolescent girls between 10 to 19 years old places Anorexia Nervosa and Bulimia Nervosa as two of the most common chronic illnesses of their age group (Stice and Agras, 1998; Lucas et. al, 1991).

For this reason, numerous studies have tried to determine the culprit(s) of these disorders and most systematic investigations found that the way media portrays the "ideal" body of a woman serves as the most influential factor. According to Spitzer, Henderzon, and Zivian (1999), as the media show advertisements featuring female endorsers with slim and skinny bodies, more and more cases of eating disorders among young and adolescent girls became apparent. Clearly, this is not a coincidence since the society's level of exposure to the so-called "western ideal" of thinness is highly associated to the number of young males and females who have eating disorder tendencies.

A lot of researchers also documented a strong association between the eating disorder development and the exposure to the western ideal of thinness. As a matter of fact, this association can be seen in both developed and developing countries. Becker et al. (2002) discussed, that the introduction of television and internet has paved the way for the increased occurrence of "disturbed" eating behaviors and attitudes among elementary school girls in Fiji, Japan. Presumably, this is due to their exposure to the "thin" ideal. The research of Unikel, Aguilar and Gomez-Peresmitre (2005) in Mexico confirmed a model in which having a body with excess weight increases the chance of body discontentment among young school girls. On top of that, the pressure to be thin as well as the internalization of the ideal to be thin also served as contributing factors to the development of eating disorders in Mexico. In the United States, the research of Groesz, Levine, and Murnen (2002); Cafri et al. (2005); and Stice and Bearman (2001) were only a fraction of scholarly papers which provided a strong evidence of the relationship between pressure to attain, awareness of, and exposure to the "thin" ideal and body dissatisfaction.

It is globally accepted that the main sufferers of the eating disorders are women, particularly young and adolescent girls. In fact, both anorexia and bulimia were 
tagged as "maiden diseases". According to Neuman and Halvorson (1983), young girls back then were literally "dying to be beautiful" since the cases of Anorexia Nervosa alone recorded a $4 \%$ to $25 \%$ mortality rate in the early 80 's. Although binge-eating, commonly known as Bulimia, was officially coined during the same decade, it instantly became a very popular eating disorder since it involved frequent episodes of excessive eating/drinking followed by exercising, purging, or compensatory fasting. Moreover, majority of the studies also showed that young girls and middle class women are more prone to these eating disorders compared to other classes.

\section{Methodology}

276 children aged 9 - 12 from Bratislava, who completed the children's version of the Eating Attitudes Test (ChEAT), reported whether they had ever wanted to be thinner or tried to lose weight.

The ChEAT appears to be valid and reliable as an early diagnostic tool at this time. However, it often requires further follow up using other diagnostic exams to verify if the score is high for a child. Research results show that the ChEAT can be considered as a primary diagnostic tool for eating disorders, yet if a child scores in the upper percentiles, other diagnostic tests can be used to investigate the disorder further. The question of the prevalence of the yearning to be thinner among the children in this study is critical. Another factor to be considered is what the division of this desire between males and females would be. The "Children's Eating Attitude Test" is often administered to children who have tried to lose weight or have complained that they feel too fat and are looking for approval from peers by becoming thinner. The children who displayed these characteristics score significantly higher on the ChEAT than children who are not displaying these characteristics. Dieting behaviors and the preoccupation with food in this age group can range from bulimia and anorexia to mild concerns about weight. The ChEAT is one of the ways to evaluate children in this age group for these conditions, however it is not meant to be a comprehensive diagnostic test for an eating disorder (Ontario Centre of Excellence for Child and Youth Mental Health, 2012). Nonetheless, it may be used to assess the children suspected of having disorders in their eating habits and guide their physicians and caretakers as to whether they need more intervention. Properties of the ChEAT test include 26 items that are rated on a six-point scale with six responses. Scoring the ChEAT is a matter of adding the number of responses on the test that are indicative of an eating disorder. The ChEAT includes three sub-categories for factor analysis namely: dieting, restriction and purging, and food pre-occupation, that were also factored in the original EAT test. ChEAT is a modified version of the original that delves into questions pertaining to the perception of body image, obsessions and 
preoccupation with food, and dieting. After which, it then evaluates each of the 26 questions using a Likert-type scale. The Likert scale is a sum scale of alternatives to which a testee may respond by a circle or other mark on an item in order to obtain a score on a test. The ChEAT was reduced and simplified for use with children as young as eight years of age. No particular qualifications are specified for scoring or for the interpretation of the ChEAT, although the higher the score, the more likely the child is to have a proclivity to an eating disorder. Scoring on the ChEAT ranges from 1 to 156.

In this study, the survey sample were 276 children aged $9-12$. They were tested using the ChEAT test. Directives for the test were given to the children orally and the test was taken as a written examination. The test had six answers for each item. The top three answers with high scores were "always", "very often" and "often". These three answers were scored 1, 2, and 3. With the scale being $0-78$, a score of 20 indicated an eating issue with the child. It did not necessarily indicate an eating disorder; however, it would be an indication for further investigation. To investigate the perspectives and evaluate the behaviors that are common to eating disorders and weight obsession with children, the ChEAT was created as a primary diagnostic tool. The children reported whether they wished to be thinner or to lose weight.

\section{Results}

These results are comparatively similar to the first set of results verifying the validity and reliability of the ChEAT as a primary step in diagnosing eating disorders in the selected age groups for this exam. The interpretation should be cautious because the items do not distinguish between some normal childhood events and those that might be clinically relevant. Maloney et al. (1988) suggested that ChEAT scores of 20 or higher can be regarded as above threshold in screening for eating disorder.

The weight range in our study has a few significant elements. For males, the weight range is between 35 and 45 . Females showed a greater discrepancy; while the heights remained generally in the same range, the weight ranged from 25 to 40 . Percentages reporting various eating and weight-related behaviors were as follows: dieting $23 \%$, exercising $62 \%$, binging $24 \%$, and vomiting after eating $3 \%$. If compared to boys at risk (8\%), a slightly higher number of females $(15 \%)$ were, based on their ChEAT score, in the risk zone.

The results of the Australian research, as for the percentages, were similar to the results of our study. The similarity lies in the higher number of females in the risk area. Generally, children in the fourth grade scored higher than in grades five and six. In this study, all the children are 9 years old and their scores were fairly high compared to the correlation in the Australian study. The Australian evaluation reflected that girls were $28 \%$ above the threshold while boys were $9 \%$ 
above. Similarly, the Bratislava study showed that more females (32\%) than males $(11 \%)$ were at risk. Based on the Australian study, the high risk scores were significantly lower for both 11 to 12 years old males and females, only showing a total of 3 at-risk scores when combined. This is in opposition to the high scores of nine year-old children mentioned in this study. "There exists little published research on the behavioral phenomenon of extreme "picky eating," or selective eating, in middle childhood" (Rolland, Farnill and Griffiths, 1995). These studies contribute to a positive change and further research will follow.

In this study, the correlation between BMI and at-risk threshold scores on the ChEAT tallied substantially with those children who scored higher on the ChEAT having lower BMI scores. This also correlates with other studies. In the Australian study, children who scored higher (in the upper quartile) of the test, reflected heightened concern about being overweight and their BMI scores were lower than of those who were in the lower quartile range.

\section{Discussion}

The results of this study resemble the Australian study which correlated similarly with studies done in Israel and the United States. Children in the younger categories show a higher risk for eating disorder and body image issues than older children. In all of the studies, there was a correlation between the ChEAT scores and their BMI. As the score increased, the BMI decreased in both this and the Australian study, which indicates that children in the high risk category were actively trying to lose weight or were concerned with their body image and were actively engaged in a weight loss activity ranging from anorexic behavior to dieting. A children's hospital says that Anorexia Nervosa is up among diet-crazed girls as young as 8 years old who are worried about their weight because of social pressure (Anorexia Hits British Youth, 1990). This study is significant as it is the first of its kind done in this area of the world. The correlations to other studies are indicative of a global response to younger children being intensely occupied with body image. Further studies need to be conducted with children on body image. As this study did not use visual aids, the ChEAT indications, BMI scores, and the loss of intense interest in body image as the children age, seems to be similar across the cultural boundaries. "Usually the onset [of an eating disorder] is during puberty, early teenage years, but it doesn't mean they are getting treatment at the onset of the condition" (Gillespie, 2012). More children need help because of eating disorders and this study is confirmation of that fact. As these studies come out, more people may seek treatment for eating disorders. Currently, "programs that admit and treat patients with eating disorders are more likely to emphasize a medical-psychiatric model of addiction, use psychiatric medications" (Weiss, 2007). Hopefully, this will prevent a long-term damage from eating disorders. 


\section{Conclusions}

The research showed that there was a definite risk for younger girls to have body image issues, but boys were at risk as well. Geographical differences do not play a significant role in the body image issues that children encounter. The global issue of body image appears to affect children at a young age, as the results of this and the Australian study show. While more research is needed to discover how much cultural values and other factors may affect body image in children, at this point it appears that children are vulnerable and that age is the primary factor in this. Teens are likely to have body image issue, however, the age group that seems to be most affected seems to be the preteen group. The Likert is a useful measuring scale used in both studies. Other scales and tests, such as the MMPI, may give more insight in these issues. At this time, the Australian research results were confirmed and verified by the Bratislava study. Children as old as 8 years up to their teenage years should be monitored for eating disorders if they are low on the BMI chart and exhibiting behaviors that indicate that they are at risk of having eating disorder and body image issues.

Recognizing the specific factors that cause a child to suffer from an eating disorder is extremely important. Finding adequate solutions to thwart children's eating disorders at their onset can avoid severe health problems during their later lives. The best way to help children overcome inferior perceptions about their physical appearance is through adequate guidance from their parents. Making the child perceive weight gain as a normal part of growth especially during puberty and discussing media messages pertaining to body image can help children to accept themselves and to feel comfortable in their bodies. For teachers, the data demonstrate the need to increase the number of educational materials and instructions that teach children to take care of their health and to resist pressures that glamorize negative body perception and counterproductive lifestyle habits. Integrating lessons on positive body image and self-care into the school curriculum will go a long way towards helping kids to grow up with a healthy self-esteem.

\section{References}

Anorexia Hits British Youth. The Gazette [online], 1990, 2-A2. Available from: http://search.proquest.com/docview/432025888?accountid=28180

BECKER, A. E. at al. Eating behaviours and attitudes following prolonged exposure to television among ethnic Fijian adolescent girls. British Journal of Psychiatry, 2002, 180, 509-514.

BRYANT-WAUGH, R. and LASK, B. Annotation: Eating disorders in children. Journal of Child Psychology and Psychiatry, 1995, 36, 431-437. 
CAFRI, G. et al. The influence of sociocultural factors on body image: A metaanalysis. Clinical Psychology: Science and Practice, 2005 12(4), 421-433.

GILLESPIE, K. Bay children aged 11 suffer eating disorders. Bay of Plenty Times [online]. 2012. Available from:

http://search.proquest.com/docview/1018677638?accountid=28180

GROESZ, L. M., LEVINE, M. P. and MURNEN, S. K. The effect of experimental presentation of thin media images on body satisfaction: A metaanalytic review. International Journal of Eating Disorders, 2002, 31(1), 1-16.

LUCAS, A. R. et al. 50-year trends in the incidence of anorexia nervosa in Rochester, MN: A population-based study. American Journal of Psychiatry, 1991, 148(7), 917-92.

MALONEY, M. J., MCGUIRE, J. B. and DANIELS, S. R. Reliability testing of a children's version of the Eating Attitude Test. J Am Acad Child Psy. 1988; 27(5): 541-543.

NEWMAN, P. and HALVORSON, P. Anorexia Nervosa and Bulimia: A Handbook for Counselors and Therapists. New York: Van Nostrand Reinhold Company, 1983.

Ontario Centre of Excellence for Child and Youth Mental Health. Children's Eating Attitudes Test (Ch-EAT) [online]. Ottawa, 2012. Available from: http://www.excellenceforchildandyouth.ca/support-tools/measureprofile?id=76 ROLLAND, K, FARNILL, D and GRIFFITHS, R. Body figure perceptions and eating attitudes among Australian schoolchildren aged 8 to 12 year olds. Department of Behavioral Studies, Sydney Australia, 1995.

SPITZER, B. L., HENDERSON, K. A. and ZIVIAN, M. T. Gender differences in population versus media body sizes: A comparison over four decades. Sex Roles, 1999, 40, 545-565.

STEINER, H. and LOCK, L. Anorexia nervosa and bulimia nervosa in children and adolescents: A review of the past 10 years. Journal of the American Academy of Child and Adolescent Psychiatry, 1998, 37(4), 352-359.

STICE, E. and BEARMAN, S. K. Body-image and eating disturbances prospectively predict increases in depressive symptoms in adolescent girls: A growth curve analysis. Developmental Psychology, 2001, 37(5), 597-607.

STICE, E. and AGRAS, W. S. Predicting onset and cessation of bulimic behaviors during adolescence: A longitudinal grouping analysis. Behavior Therapy, 1998, 29, 257-276.

UNIKEL, C., AGUILAR, J. and GOMEZ-PERESMITRE, G. Predictors of eating behaviors in a sample of Mexican women. Eating and Weight Disorders, 2005, 10(1), 33-39.

WEISS, F. Assessment of eating disorders. American Journal of Psychotherapy [online], 2007, 61(1), 100-102. Available from:

http://search.proquest.com/docview/213108778? accountid=28180 